\title{
نقاط التحول
}

\section{عندما تأخذ الحياة اتجاهاً جليداً}

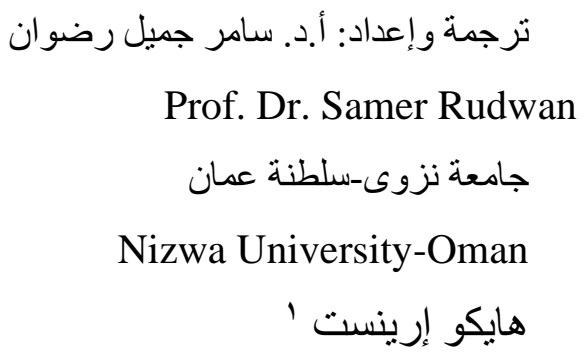

كل حباة هنالك نقاط عدة من التحول. إننا نريد أو لابد لنا من إنهاء مرحلة من مر احل الحياة و البدء بمرحلة أخرى. وأحياناً تثكل الأزمات والانكسارات نقاط التحول ـ البطالة والطلاق يخرجاننا عن السكة، وأحياناً نكون "اللا أحداث" هي التي تجبرنا على البدء من جديد ـ لقد انتظرنا

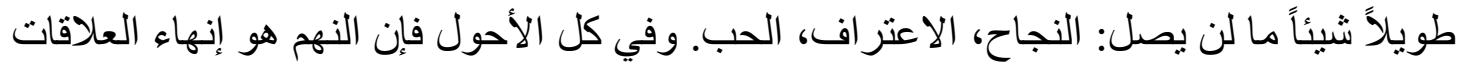

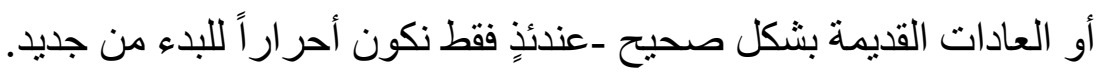

بستلقي بينيامين متهادياً على فراش هو ائي في حوض السباحة بمنزل والديه. فهو منذ عدة أسابيع يتسكع في البيت على هذا النحو، وقد بدأ قعوده يوتر والديه. وحتى النصيحة التي أسر له له بها أحد أصدقاء والده في العمل و التي تقول: ("لن أقول إلاّ: بلاستيك!؟") لم تعطه أي دفع. كان بينيامين ـالمعروف باسم دوستين هوفمان ـ قد أنهى تعليمه، غير أن "الامتحان النهائي" الحقيقي

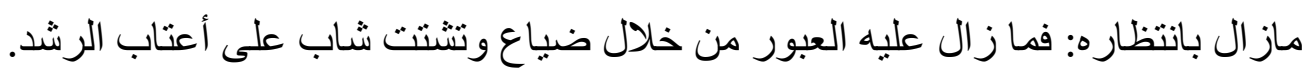
أصبحت الحياة المهنية "للأب" لوريونس3"("Pappa Ante Portas") وراءه. إنه يمثل

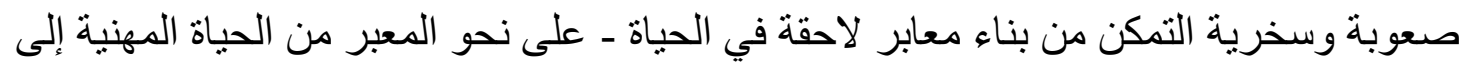

${ }^{1}$ Heiko, E. (1997). Wendepunkte: Wenn das Leben eine neue Richtung nimmt. Psychologie Heute, Oktober, 1997 (20-26).

ץ في الفيلم الكلاسيكي "الامتحان النهائي" يحصل بن على نصيحة حسنة النية منذ البداية:" سأخبرك بكلمة واحدة، كلمة واحدة،

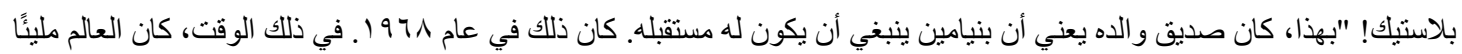

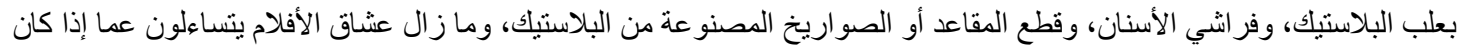
الاقتباس المذكور في البداية هو أكثر حقاً عن السيدة جوارب النايلون للسيدة روبنسون. 3 فيلم صدر في عام 1991 
التقاعد: فالمنقاعد لم ينقبل خروجه بشكل حقيقي وحاول "تنظيم" حباة الأسرة كما اعتاد ذلك في المهنة. وما كانت النتيجة إلا: فوضى كلية.

إننا نحب بعض الأفلام والمسرحيات لأننا نرى فيها أزمات ومتاعب حياتنا الخاصة. فعندما

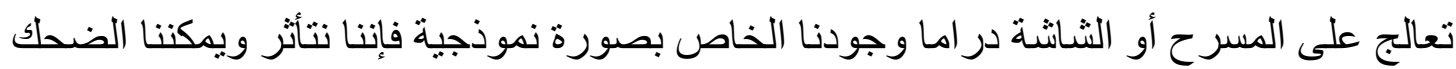

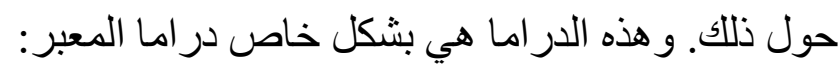
فحياة الإنسان ما هي إلا نتيجة لأطو ار بارزة كثير أ أو قليلاً. وتتعلق الصحة النفسية وسعادة

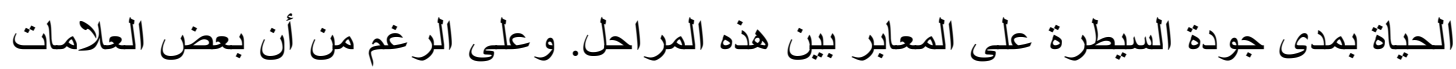

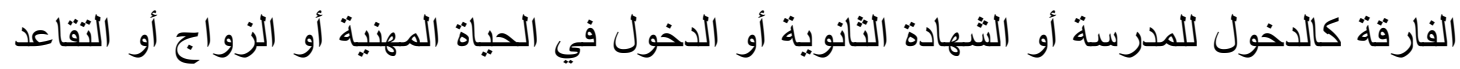

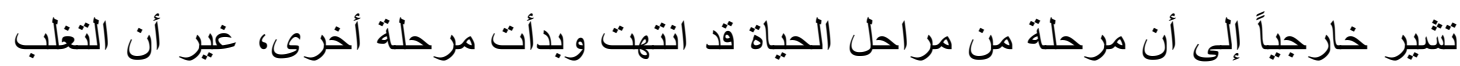
النفسي على المعبر لا ينم دائماً. فإلى جانب نقاط التحول المحدة ثقافياً أو زمنياً ــ المُعَلَّمة بالدخول إلى المدرسة أو خاتم الزواج أو بالساعة الذهبية التي تهدى إلينا في التقاعد ـ تخبئ الحياة عدداً كبيراً من نقاط التحول

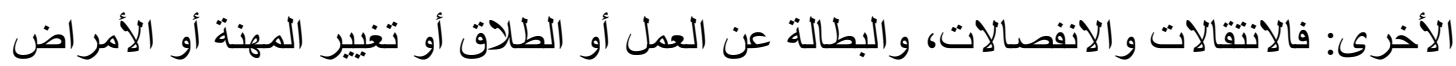
ناهيك عن الأحداث الإيجابية كالترقيات ونمو الأسرة تجبرنا ـ أو تتيح لنا ـ الانطلاق من جديد.

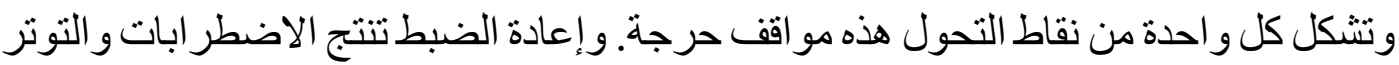

$$
\text { وفوضى المشاعر و المخاوف و عدم الأمان. }
$$

ناهيك عن أن إمكانات خسران معبر ما متنو عة؛ إذ قد يظل المرء غارقاً بما هو قديم، بما هو مألوف، أو يغرق في الإمكانات الجديدة أو يحمل معه الكثير من الأثقال النفسية من المر احل الحياتية السابقة إلى المرحلة الجديدة. إن من يصل إلى نقطة تحول في حياته عليه التغلب على ثلاث خطوات: ا إيجاد نهاية: فكل بداية جديدة تبدأ بنهاية ولا بد من إنهاء و "إغلاق" العلاقات والعادات

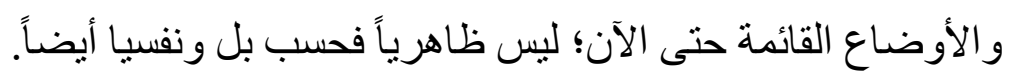

r- إعادة التوجه: فنقاط التحول تثنكل فرصة لتصحيح المسار وللنمو الثخصي -ومن أجل ذللك

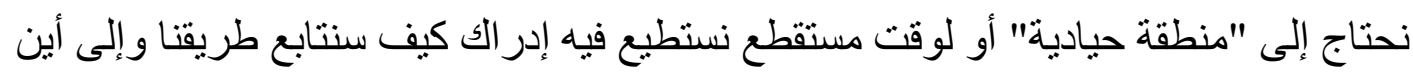


بـ البدء من جديد: عندئذ يمكن أن يتم دفع التطور الشخصي و القيام بالبداية الجيدة، وبشكل متحرر من الأشياء "غير المنجزة" من المر احل السابقة نحو هدف جديد.

وتثبه الخطوات الثلاثة طقوس العبور rites de Passage التي لاحظها ووصفها عالم الأجناس الهولندي أرنولد فان غينيب Arnold van Genepp في التقافات التقليدية. وتدور هذه الطقوس حول ثلاثة أطوار من العبور: الموت الرمزي والقوضى والخلق. وفي المجتمع الحديث لم يعد يوجد إلا القليل من الطقوس التي تسهل للفرد العبور من طور حياة إلى آخر. و على الإنسان أن يتعرف بنفسه على نقاط التحول ومو اجهة أزمات تغيير الاتجاه وحده في الغالب. وهو يجد نفسه أمام ضرورة التعامل مع التصدعات و التغير ات في اتجاهات برنامج الحياة، أكثر بكثير من الناس في العصور السابقة. ولعل التبديل المستمر للاتجاه والبدء من جديد أقرب لأن يكونا من العلامات المميزة لمسيرة حياة أناس مجتمع ما بعد الحداثة: فعدد التبديل الاختياري أو القسري للمهنة و السكن أو أرقام الطلاق تظهر من الناحية الإحصائية الخالصة وحدها مدى الحر الك الاجتماعي و النفسي في هذه الأثناء. أن مسيرة حياة أناس هذه الأيام تتميز بحتمية التعلم مدى الحياة وإعادة التلاؤم المستمرة و التبديل المتعدد للأدوار.

\section{المشكلة تكمن في إيجاد نهاية جيدة}

إننا نطور منذ وقت مبكر من الحياة " أساليب شخصية من المعابر": هل يصعب أو يسهل علينا البدء بشيء ما جديد والتخلي عن القديج؟ وهل نحن "متشبثون" لا نستطيع الترك إلاّ بصعوبة أم أننا أقرب "للمتهورين"، من السهل علينا أن نبدأ من جديد؟ فلو حاولنا استرجاع مواقف الانفصال و العبور من الذاكرة فلسوف نستخلص منها مؤشرات على الأسلوب الذي سنقود فيه نقاط التحول في المستقبل أيضاً. ومهما يكن نوع الأسلوب الذي طورناه ـفعند الخطوة الأولى لعبور ما يمكن أن نرتكب الكثير من الأخطاء: إذ يصعب على كل إنسان تقريباً إيجاد نهاية جيدة؛ فعلى الرغم من أن ثقافتنا تفضل أسلوب الانفصال السريع، فقد تعلمنا أنه على المرء "إلا يولول على الحليب المدلوق" وبأن لكل شيء نهاية في الحياة و على الإنسان التطلع للأمام و إلى ما أكثر من حكم الحياة اليومية. ووفقاً لذلك فعندما يلوح المعبر فإننا نريد "الخروج" بسر عة كبيرة قدر الإمكان ونبدأ من جديد، وناسف أو ننتقد أولئلك الذين 
يصِيِبون على أنفسهم إيجاد نهاية. ولكن لابد من تمثل أو استيعاب كل نهاية وهذا التمثل أو الاستيعاب يحتاج إلى وقت كافٍ. فمن يجتاز خسارة ما (كالموت أو الطلاق) أو تغيير مهم (كالانتقال أو تغيير المهنة) بسر عة كبيرة فإنه يخاطر على المدى البعيد بحدوث مشكلات نفسية.

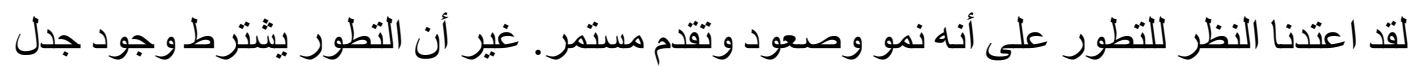
بين التهديم مew-Organization وإعادة التنظيم New-Organization، الذي يتم دفعه للأمام عبر الخسارة بالتحديد أيضاً: ففي البدء لا بد من نسيان أو التخلص من شيء ما قبل أن يتم التمكن من تعلم شيء جديد.

تنتر افق أزمات الحياة التي تفتح باب الوداع و إعادة التوجه مع واحد أو أكثر من السمات التالية:

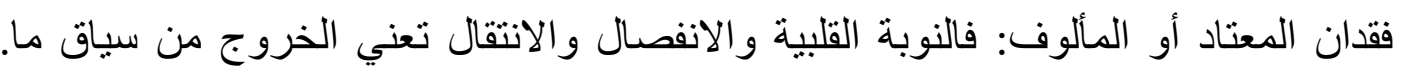
فظروف الحياة الخارجية تتغير بسر عة وتتطلب تكيفاً. فقدان الهوية: تتتج غالبية نقاط التحول الثعور المقبض المتمثل في: " أنا الذي يحدث معه ذلك؟ ليك ما الذي فعلته في الواقع؟ "إننا نقف إلى "جانب أنفسنا " ولكننا لم نعد " نحن أنفسنا ". فقدان الأو هام: توجد في كل حياة سلسلة لا متتاهية من الخيبات. فمنذ الطفولة علينا إدر الك بأنه

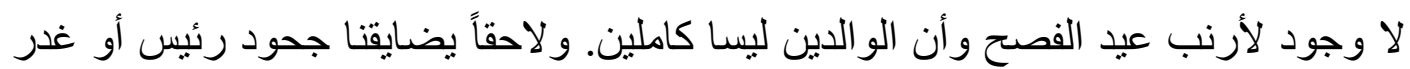
صديق. وتتكثف غباء وأنانية المعبودين (رجال الدين والسياسيون و النجوم /المترجم/). والسياسيون القلائل الذين يعتبرهم الإنسان شرفاء فاسدون كالآخرين تماماً، وشريك حياتنا يسيء استخدام ثقتنا به. وتتحول الإجازة إلى رحلة مقززة، وهكذا دو اليك. ويفترض للخيبات أن تقود إلى تصديحات للتصور ات المثالية (غير الواقعية): فبمجرد أن نتخلى عن الأوهام يمكننا التعلم من جديد. غير أن الخيبات غالباً ما تشكل مناسبة للإزعاج إنهاج

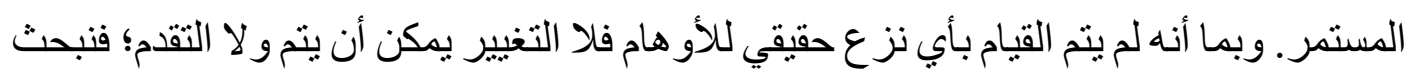

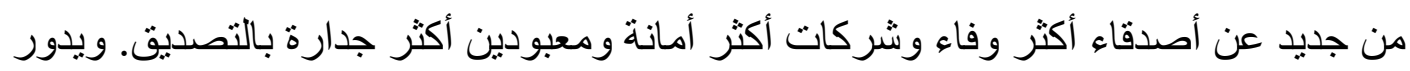

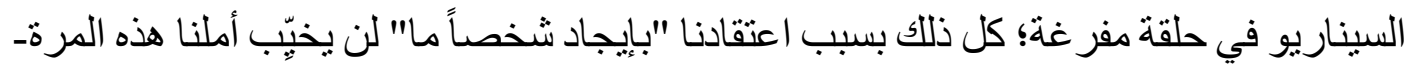
طبعاً إلى حين حصول الخيبة التالية. أو أننا نشعر بالمر ارة و السخرية ونصبح شكاكين مزمنين. فقدان التوجه: عندما ينتهي شيء ما فإن الجديد على الغالب غير موجود بعد. إننا نشعر بالفشل و الضياع والفراغ الداخلي. ويشبه هذا في ميثولوجيا المعبر الطور الذي يهيم فيه البطل على لهي وجها في حديقة الضياع أو في غابة ما أو عندما يبتلعه حيو ان. الفراغ المفيد للوقت المستقطع 
وحتى عندما نكون قد أدركنا حقيقة أن شيء ما قد وصل إلى النهاية، فإننا لم نبلغ قمة الجبل

بعد. إننا نجد أنفسنا في موقف غير مألوف؛ ها نحن قد وطئنا شريط المنطقة الحيادية: فطور العبور الحقيقي هو الزمن "بين حلمين". مرحلة حياتية قد انتهت ولكن الجديدة لم تبدأ بعد فيط (بالفعل). إننا لا نستطيع تحمل هذه الأوقات الفارغة إلا بصعوبة -ونحن نميل اليوم إلى الاندفاع

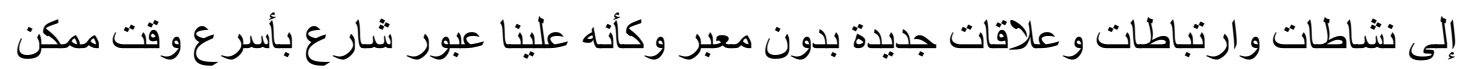
للوصول إلى الجانب الآخر منه. غير أن المنطقة الحيادية عبارة عن تعليق للنشاطات، على درجة

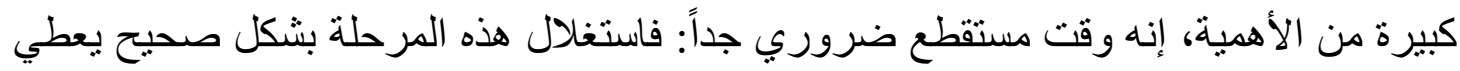

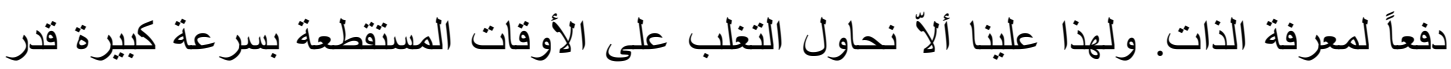

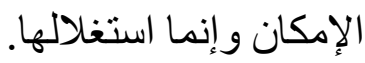

فعندما نترك أنفسنا تسقط في فر اغ هذه الأوقات المستقطعة، فإننا نرى فجأة بشكل أكثر دقة، وندرك محيطنا بشكل أكثر حساسية. إننا نكتسب البعد عن الحياة اليومية التي تتحول بطريقة غريبة فئن إلى حياة شفافة ـ نسبر أثشياء كثيرة ونرى "ما ور اء الأشياء" ونربح قطعة من حكمة الحياة. و المنطقة الحيادية عبارة عن حالة شبه توسطية quasi-meditative من الغيوبة. فكثير مما كان مكبوتأ ومنسياً ينبثق في داخلنا. إنها تساعد على الانسحاب من روتين الحياة اليومية والبحث

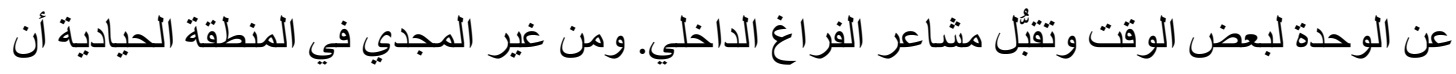

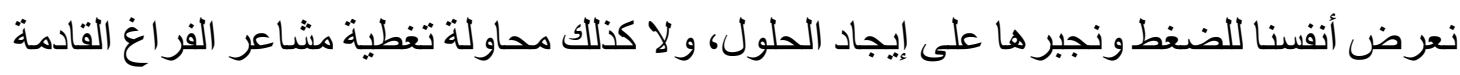
-وحتى ربما أيضاً الكآبة ـمن خلال الإلهاء و التسلية.

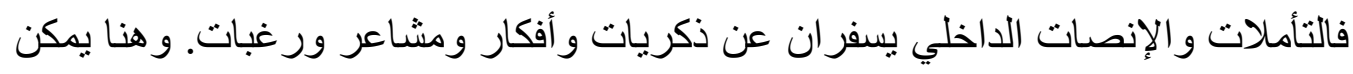
لنوع من المنهجية أن يساعد في استخدام هذه المواد من أجل التطور اللاحق: فالوقت بين مرحلتين مهم بشكل خاص للقيام بعمل موازنة حياتية (بيو غر افية) ذاتية وتقليب الذكريات الذاتية ومناقثنة

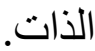

و الأوقات المستقطعة تجعل المرء حساساً تجاه رغباته ودو افعه: ما الذي أريده في الو اقع؟ ما

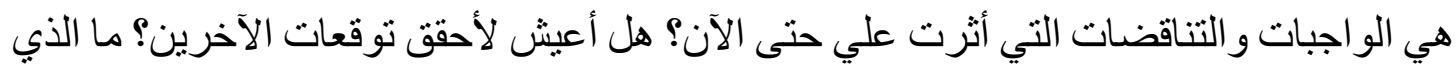

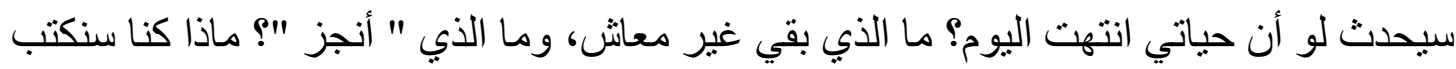
في بطاقة نعونا لأنفسنا؟ وبعد هذا التمرين على أبعد حد لابد من توجيه النظرة للأمام: وننمي تخيلات حول الكيفية

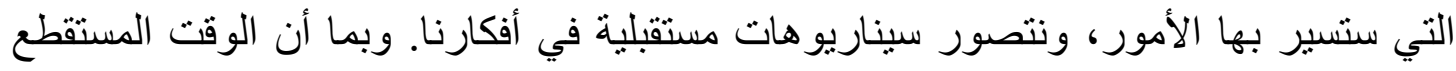


التأملي ليس هدفاً بحد ذاته ـ فعلينا استغلاله، ولكن ألاّ نتمسك به إلى ما لانهاية. فالإنسان كذلك قد يفكر كثير اً جداً بنفسه وبالطريق اللاحق. توقف عن الاستعداد!:Stop getting ready فحتى هاملت خطا في لحظة من اللحظات

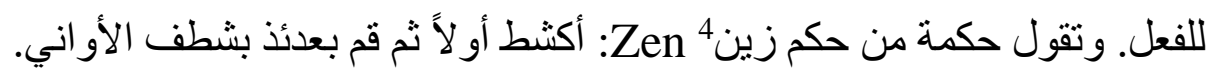

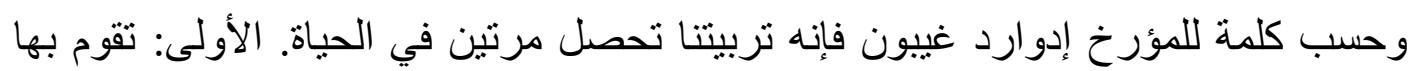

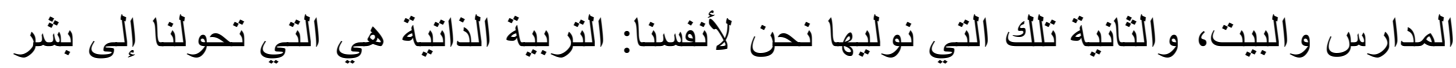
ناضجين ومثققين حقاً. وأوقات العبور في الحباة ما هي إلاّ مر احل يمكن فيها دفع التربية الذاتية

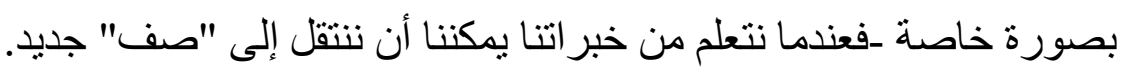

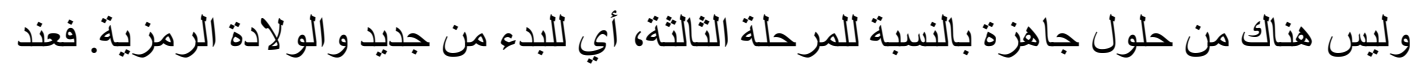

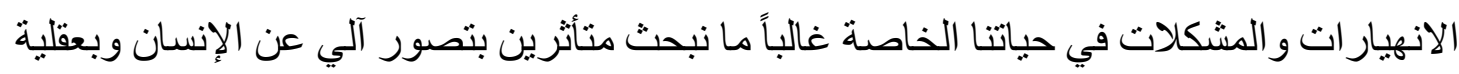

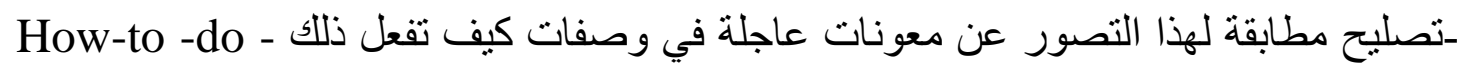
Receipts بسر عة. ولكن ليس هناك من يستطيع أن يتولى عنا مسؤولية القرارات حول طريق حياتتا اللاحق، ليس هناك من أحد يسنطيع أن يقز الترعة عنا.

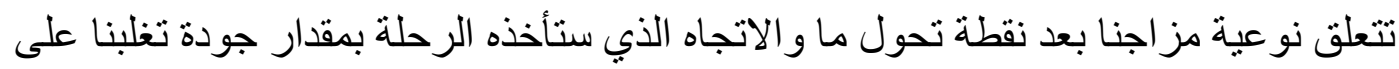
فوضى مشاعر نهاية المرحلة وملاحظة الذات في الوقت المستقطع. وكثير من البدايات الجيدة تبدأ كفكرة غير واضحة، كشعور غامض، كحس. وتبدأ صورة داخلية بالتشكل وأحيانا تثير ملاحظة عارضة لنخص محايد خبرة " آها Aha" -وفجأة يتضح الاتجاه الجديد، الدور الجديد. و البداية الجديدة ليست جديدة على النحو الذي نأمله أو نتمناه على الإطلاق: فنحن نحمل دائماء الهوية " الناضجة " من مر احل الحياة السابقة إلى المرحلة الجديدة. البداية الجديدة تعني صهر هذه الهوية القديمة مع الجديدة ودمج الخبرات السابقة في " الحياة الجديدة " بحيث لا تكون عبئًاً وتوتراً

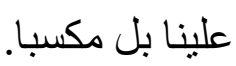


وبعد زمن الانسحاب و التأمل و الوحدة علينا أن نعد أنفسنا مع البداية الجديدة لاستجابات محيطنا أيضا. فغالباً ما يقابل محيطنا "الأنا المرممة" أو "التي تم تجديدها" بالقلق أو الثك، إنه يخشى الإبعاد أو "التخلف" الذاتي. ولكن كل معبر حتى و إن كنا مجبرين عليه يفتح فرصة للنمو الشخصي.

مأساة اللاحدث

لا تقتصر ضرورة السيطرة على المعابر في الحياة على نقاط التحول التي نحددها نحن بأنفسنا أو على الأحداث الخارجية التي نصطدم بها. فعندما لا يكون مفرق الطريق معلماً بوضوح تصبح المهمة أصعب بكثير جداً ـأي عندما بتعثر نمونا لأن شيء ما بالتحديد لا يحصل. و "اللا أحداث" خطيرة على الصحة النفسية والعافية مثلها مثل الفوضى والأزمات المرتبطة بمو اقف عبور و اضحة. إننا نعاني من عدم حدوث شيء ما: إذ لا نجد شريك حياتنا المناسب، بل و لا حتى الحب الكبير. و لا نستطيع العمل في المهنة التي نر غب ولا تتم ترقيتنا. ولم ندرك فرصة ما كبيرة، وربما تكون هي فرصة حياتنا، ولا نحصل على الاعتر اف الذي نتوقعه، و لا نحصل على النجاح الذي نأمل، و لا نستطيع الحصول على الطفل الذي نتوق إليه، أو حتى عندما لا يقتي الابن أثرنا. إننا نأمل بشيء بلا طائل، لن يحصل، إننا ننتظر غودو Godot و "اللا أحداث" عبارة عن خيبات، بل إنها توقعات غير محققة ومجالات متصدعة. اللاحدث ليس در اما، ولكنه غالباً ما يكون مأساة صامتة. لقد انزلقنا في مأزق - و لا نرى مخرجاً: لقد استقلنا "داخلياً"، ولكننا لا نرى فرصة لترك العمل غير المحبوب. نجد أنفسنا محصورين في علاقة ولكننا لا نريد المغامرة بالطلاق فما زال الأولاد هنا والقرض العقاري للمنزل. "اللا أحداث" تتخر في وعي الذات و غالباً ما تكون أسباباً متجاهلة للاكتتابات.

إن الإحساس بتفويت شيء ما جو هري وبعدم وجود أمل يثل ويعيق التطور النفسي. ويمكن وصف الإحساس بالحياة للإنسان الذي يعاني من اللاحدث من خلال ملاحظة لهنري ديفيد ثورو،

• في انظظار غودو" (بالإنجليزية: Waiting for Godot)، (بالفرنسية: En attendant Godot) هي مسرحية كتبها الكاتب

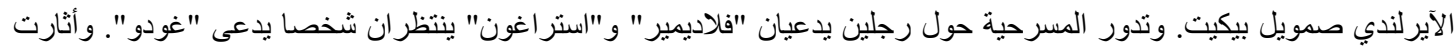

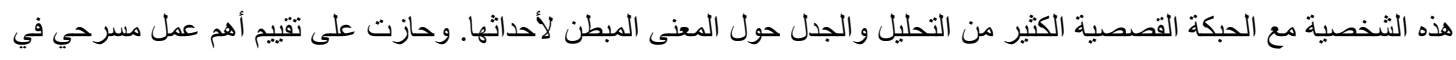

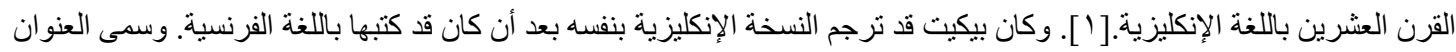

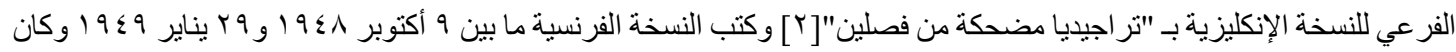

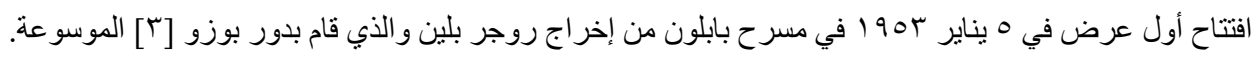
"هنري ديفيد ثورو (بالإنكليزية:Henry David Thoreau)، واسمه بالو لادة ديفيد هنري ثورو (بالإنكليزية: David Henry Thoreau )، مؤلف أمريكي ومثالي وطبيعي وداع لإنهاء العبودية وداع للعصيان الددني ومقاوم للضر ائب وناقد للتقام ومدافع عن العيش

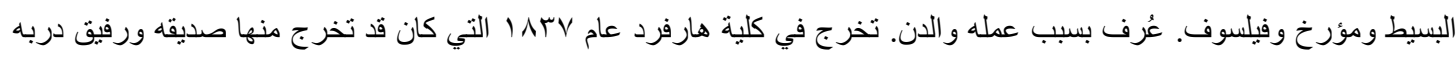


Thoreau Henry David " تعيش غالبية البشر حياتها في شك صامت ". يمكن للا_أحداث أن تحطم الفؤاد بالحرف الواحد.

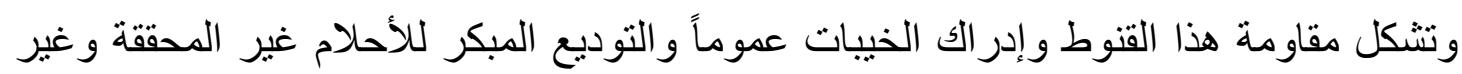

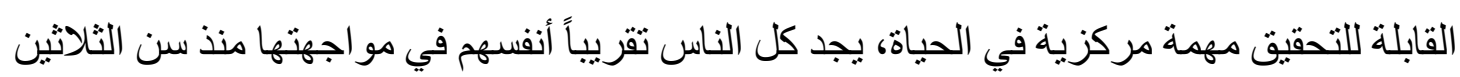
على الأكثر. ويغلب ألّّ يتم الاهتمام بهذه المهمة الحياتية لأنه من المكن أن يكون أن يكون الاعتراف

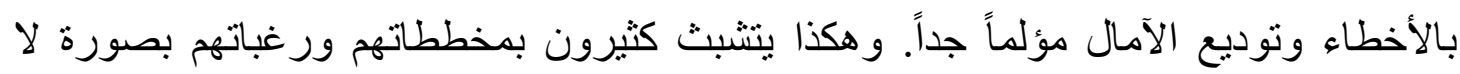
شعورية - حتى عندما يصبح و اضحاً بأنها لن تتحقق على الإطلاق. إنهم يفضلون التمسك بالتعاسة بكانة

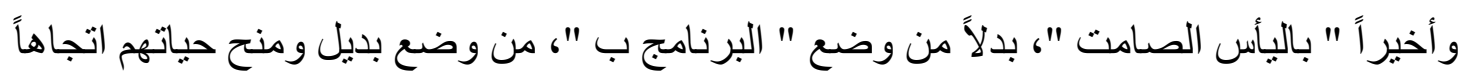
جديداً.

وغالبية "اللا أحداث" يدركها الإنسان فجأة - ير اها أمام أنفه: جو اب قاطع بالرفض لا يترك ما

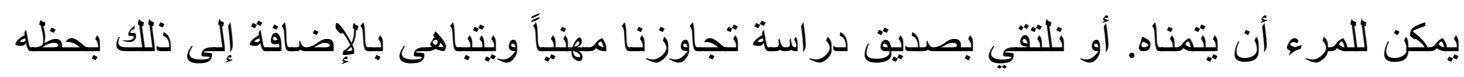

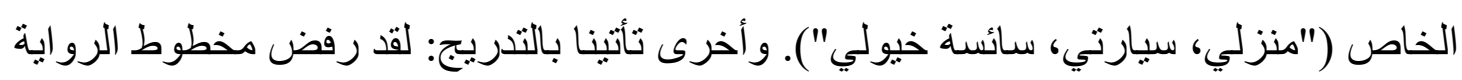

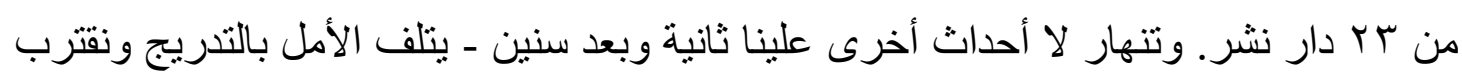

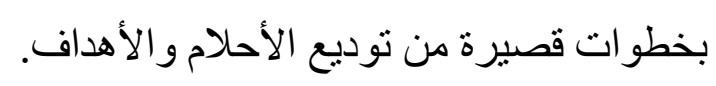

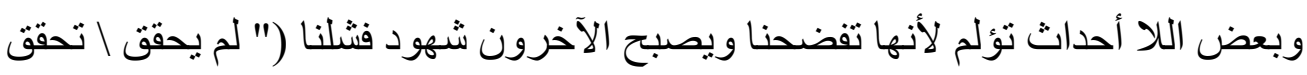

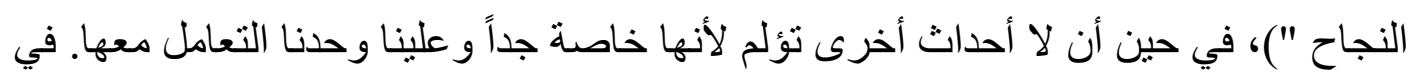

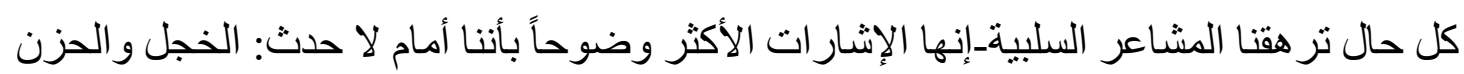
و الغضب و الحسد وكذلك اللامبالاة و البلادة.

\section{وتظلب ملاحظة "اللا أحداث" المؤلمة في بعض مجالات الحياة بشكل خاص:}

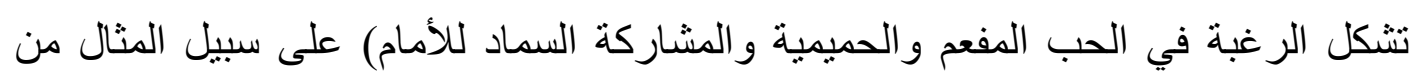

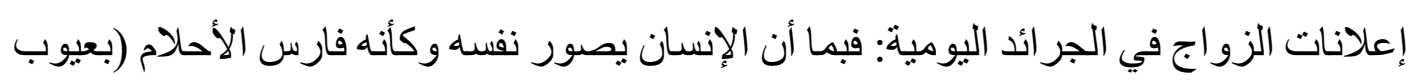

الكاتب الأمريكي إمرسون الذي تعرف منه على الفلسفة المتعالية ذات النز عة التصوفية الفردية. إلى جانب كتابه والدن (أو حياة الغابات)،

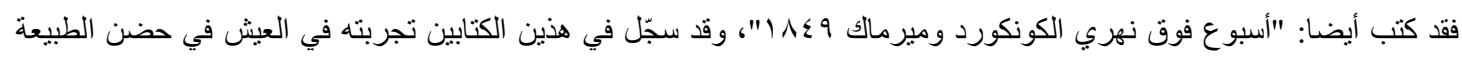

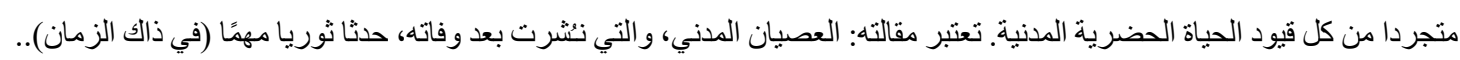

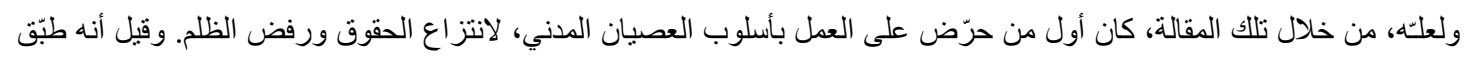

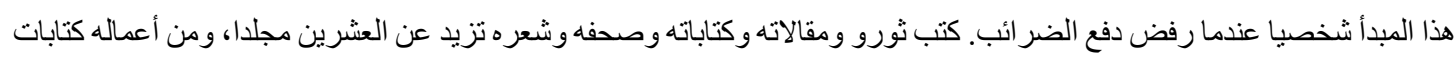
عن الناريخ الطبيعي حيث كان سباقا إلى مناهج ومختر عات الإيكولو لوجيا. الموسو عتة. 
صغيرة على أقصى تقدير ولكن محبية)، فإنه يحتمل ـ طبعاً كثريك فقط ـ أن يكمن خلف ذلك

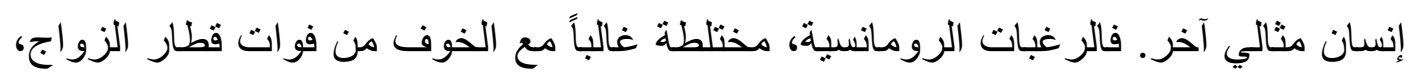

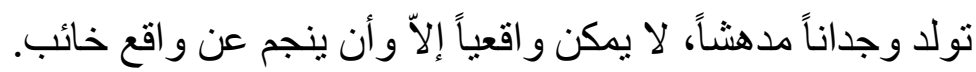
فإذا ما حصل وتم تأسيس أسرة فإنها تتحول إلى بيت بلاستيكي للا-أحداث. فالخيبات تكمن في

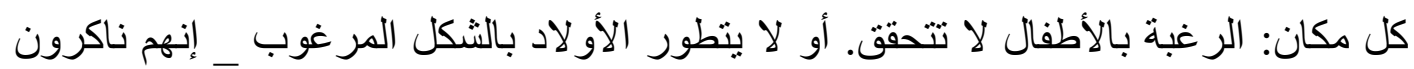

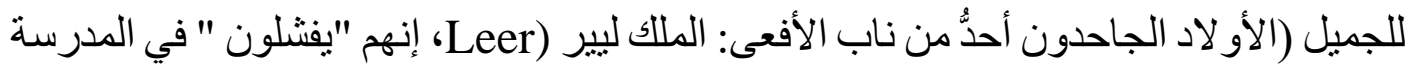

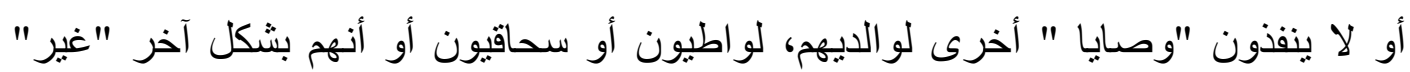
التصور ات المرغوبة. تعتبر الحياة المهنية بالنسبة لغالبية البشر أهم مصدر لكشاعر القيمة الذاتية (تقدير الذات). إن

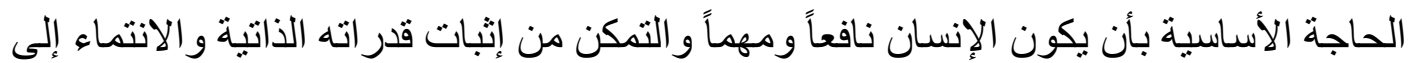

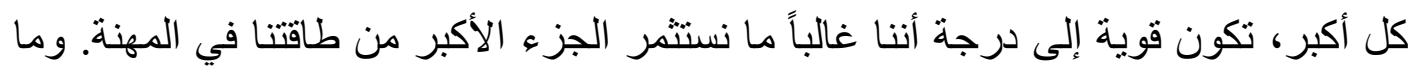

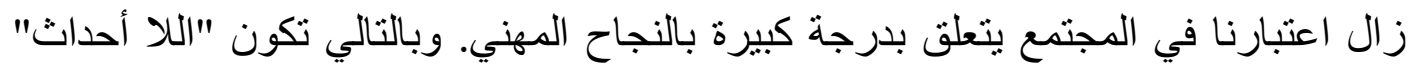

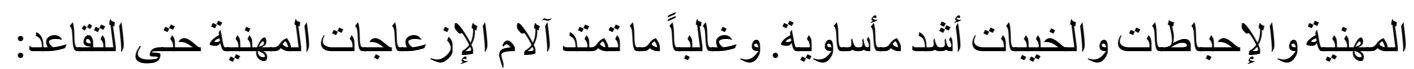

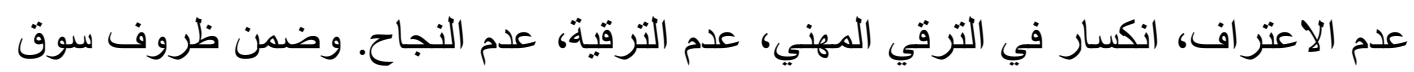
العمل الر اهنة فإن "اللا أحداث" المهنية مبرمجة: فالتطور المهني الحلم في المهنة الحلم يعتبر من الناحية الإحصائية الخالصة استثناء كبيراً، وفرص الترقي -وفق قانون الهرم -محدودة جداً؛

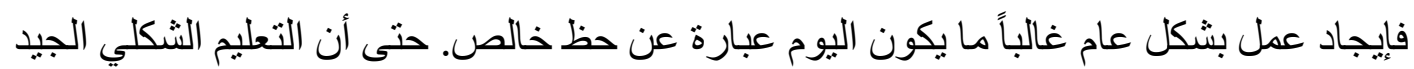
لم يعد يضمن إيجاد العمل. ومن يمتلك عملاً لا يجوز له اعتباره وظيفة ثابتة، و لا الاعتماد على لى لئل " امتنان" أو على الأقل على إخلاص مؤسسته له.

\section{والتظلب على المآزق و"اللا أحداث" المهنية يصبح أسهل عندما: لا يتمسك المر ء بثدة بهذف ير غبه، أي بسيرة مهنية محددة.} لا ينظر إلى " النجاح " من خلال رمزية الوضع الاجتماعي والدخل، وإنما من الرضى عن

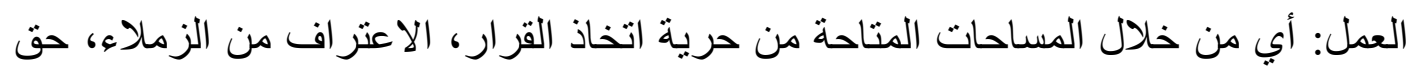
المشار كة بالر أي. يستطيع تقبل بأنه حتى عند وجود كفاءة جيدة فإن الترقي لا يمكن برمجته (حتى البابا قد وصل

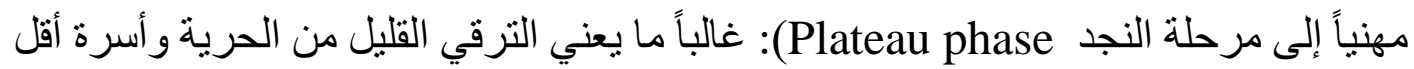
و إر هاقاً أكثر. 
وبرجع كون "اللا أحداث" سبباً لعدم الرضا والاكتتابات " و المآسي الصامتة " في حياة أناس هذه الأيام لأنهم يجدون أنفسهم في مو اجهة ضغنط توقعات رهات رهيبة:

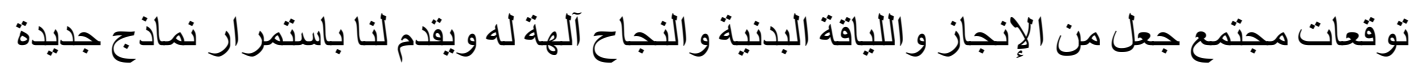

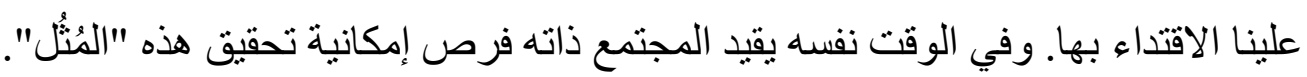

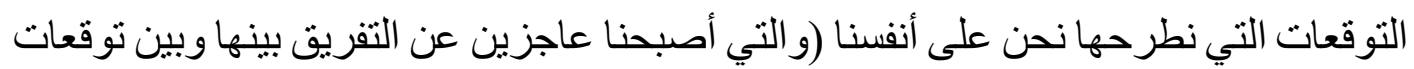

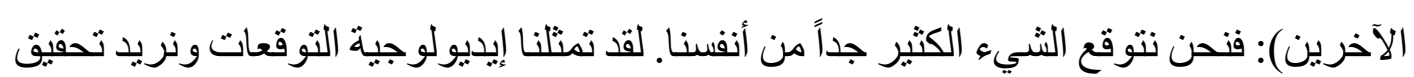

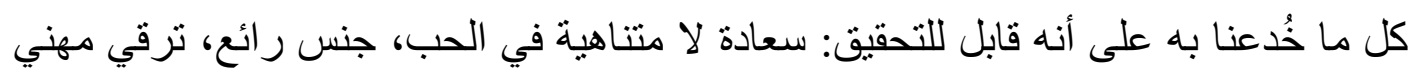
متصاعد، أو لاد مطيعون، نحافة، لياقة بدنية، إبداعية وذكاء...الخ.

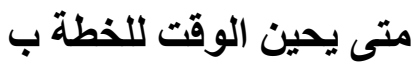
لقد استنتجت بيرنايس نويغارتن Bernice Neugarten المتخصصة بعلم النفس النمائي بأن

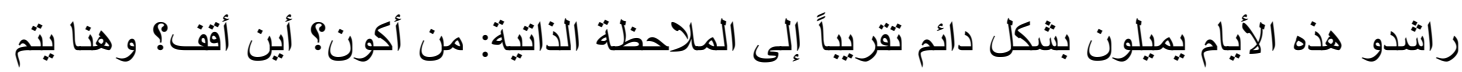

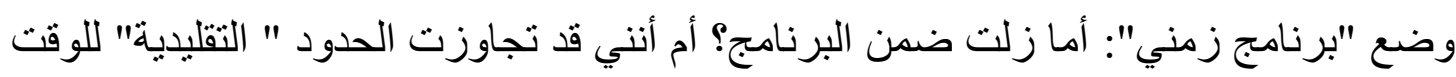
من أجل تحقيق هدف حياتي ما؟ صورتتا عن ذاتتاصارت أكثر فأكثر تنشبه تحت قهر المقارنة باستمر ار مع التصور ات المثالية،

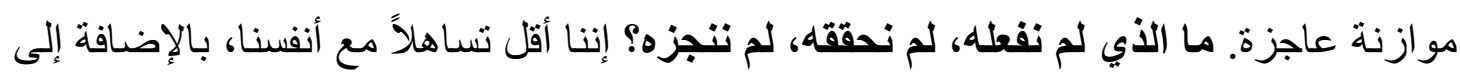

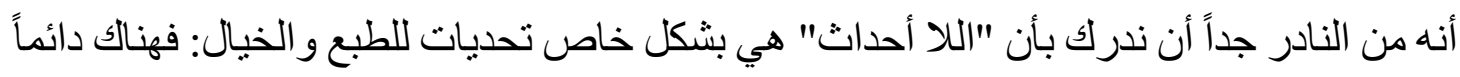

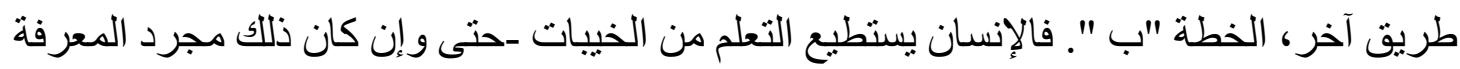
بعدم هدر وقت أطول بأهداف غير قابلة للتحقيق أو بتوقعات الآخرين. ومن أجل إدر الك فيما إذا كنا

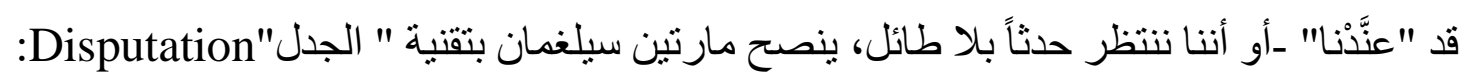

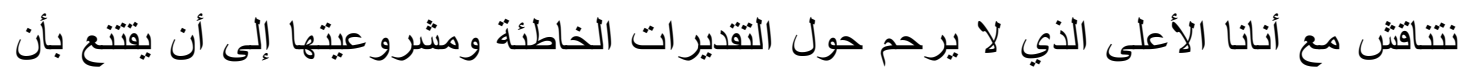
الأهداف كانت غير و اقعية وأن نقد الذات قاسياً. ويمكن التغلب على الإحساس بالثلل و الخسارة الذي ينطلق من اللاحدث عندما نحدده على أنه

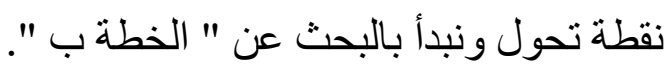
علينا أن نخضع للحقيقة وندرك الأو هام على أنها أو هام: فجائزة نوبل أو الأوسكار و اقعان خارج

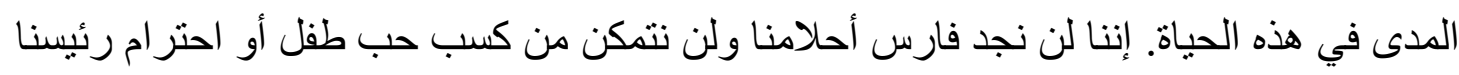

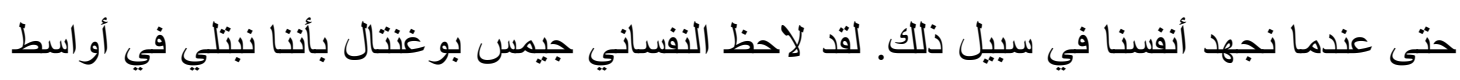

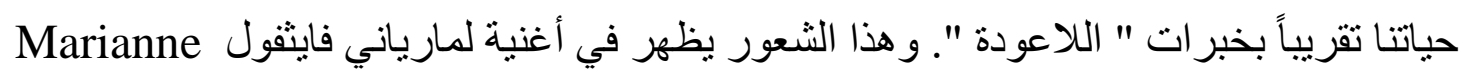


Faithful الصيف الدافئة إلى باريس ....." و عندما يساورنا الثعور بأننا قد تهنا في الحياة نبحث عندئذ ـ مثلما هو الأمر في مدينة غريبة ـ عن إحدى تلاك الخر ائط التي تظهر لنا: أنت هنا! و عندما نعرف موقعنا عندئذ نستطيع التفكير، إلى أين سنمضي؟ ما هي الطرقات التي ماز الت متاحة لي؟ ماذا أمنلك من وسائل و إمكانات؟ وبدلاً

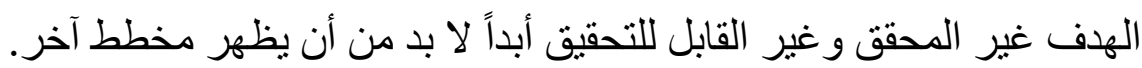

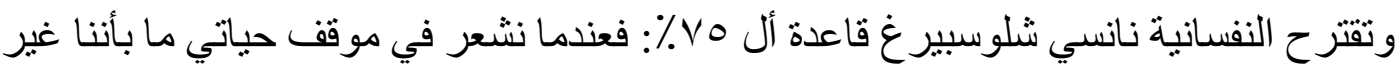
سعداء في ثلاثة أرباع الوقت ونمعن التفكير بالفرص الضائعة و الرغبات غير المحققة، عندئذ يحين

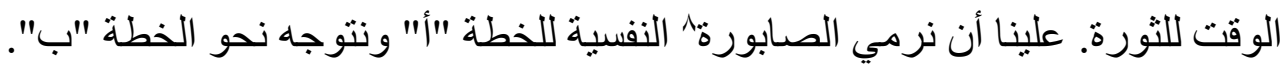

\section{برنامج المعابر ذو النقاط العشرة}

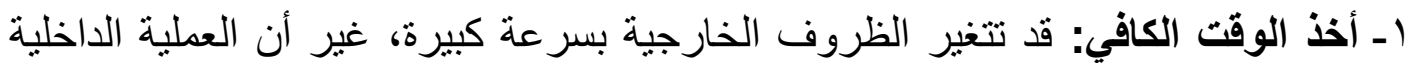

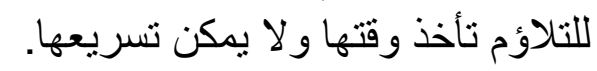

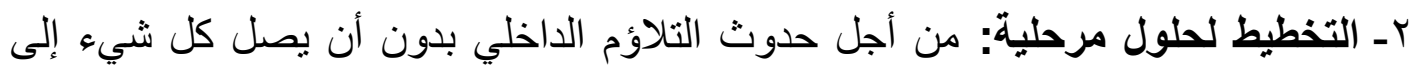

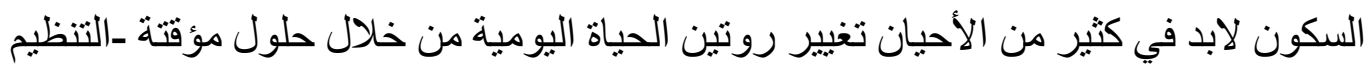

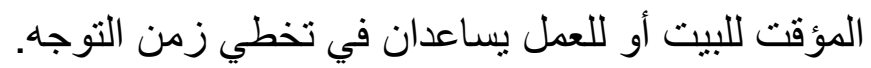

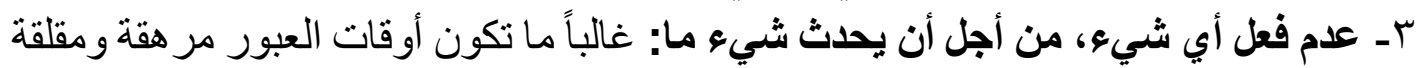

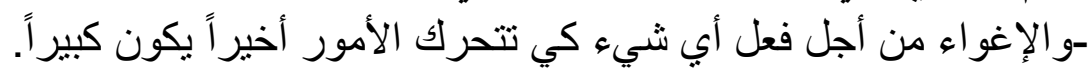

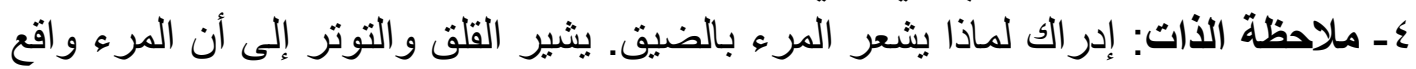
في مرحلة عبور. هـ تدليل النفس: في مراحل العبور بالتحديد تكون الاستمر ارية مهمة ـالعادات التي تمتعنا،

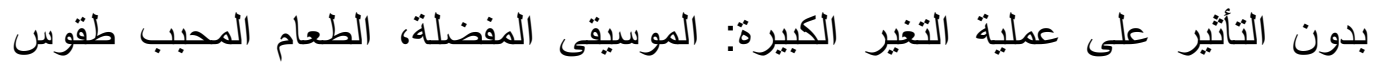
7- استقصاء " الوجه الآخر": فسواء كان التغيير اختيارياً أم قسرياً فإنه من المناسب في كل

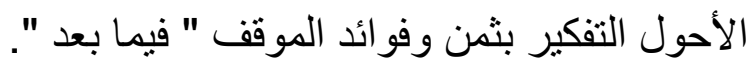

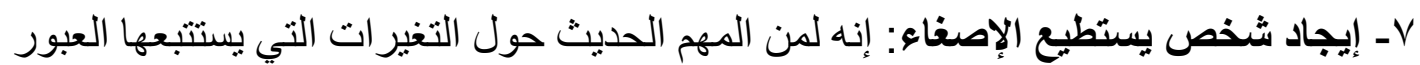

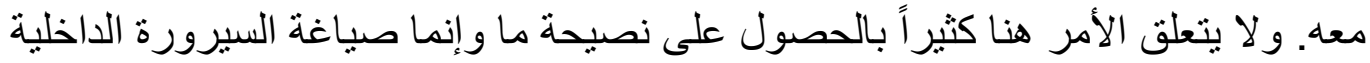

و إدر اكه بوضوح.

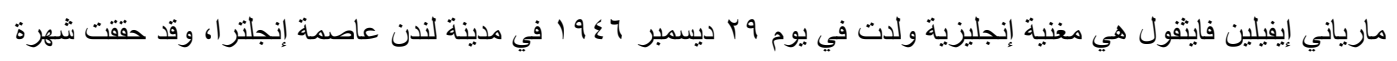

كبيرة خلال عقد الستينات و السبعينات ^ الصابورة: ثقل الموازنة وهو عبارة عن ثقل يستخدم في سفينة أو منطاد لحفظ توازنهما (المترجم). 


\section{1ـ استقصاء الإمكانات الذاتية: ما هي المو اهب و المهار ات التي كانت مهملة حتى الآن والتي

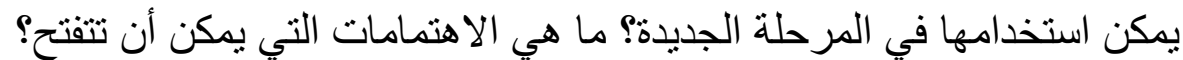

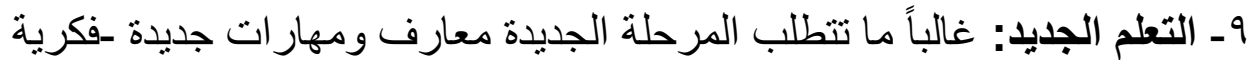

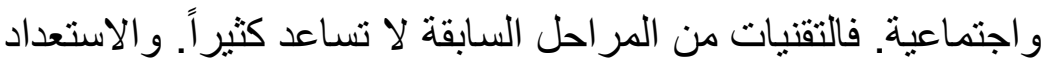 اللتعلم ضروري. \\ • 1 ـ إدرالك النمط الأساسي للمعبر: يتمثل النمط الأساسي لكل معبر بانحلال التظيم القديم وما ينجم عن ذللك فوضى ونشوء تنظيم جديد. ومما يساعد هو إدراك هذه المر احل كضرورة للتطور اللاحق والإحساس بمشاعر الفوضى على أنها مشاعر طبيعية وبشكل أقل توتراً.}

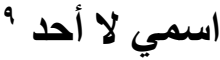

\section{النصف الثاني من الحياة كدرس في إنكار الأات}

تعد فترة أواسط الحياة بالنسبة لغالبية الناس مرحلة عبور يفكرون فيها بثدة بأهداف الحياة وتبديلات الاتجاه وبالنجاحات و "اللا أحداث": فكيف ينبغي الاستمر ار في النصف الثاني من الحياة؟ تظهر أزمة أواسط الحياة Mid-life Crisis التي كثير اً ما يستشه بها عندما تغلب "اللا أحداث": إن الشعور بتضبيع شيء ما جو هري يقود إلى أفعال تعويض مخيفة. في حين أن آخرين يغرقون في رثاء الذات، لأنه منذ الآن لن يكون إلاّ الروتين و التكرار. ولكن الاستسلام و الانفعالية Actionism خاص مع الممر القادم. أما الصعوبات التي لا بد من الالتفاف حولها في هذا الممر فهذا ما تظهره حكاية لأحد أبطال هوميروس: يمكن قر اعة الأوديسة Odyssey على أنها ملحمة النصف الثاني من الحياة أيضًاً: فرحلة العودة الخطيرة تمثل صورة التحول التدريجي في الطبع. فقد تم تتفيذ الأعمال البطولية المشكوك بها في الإلياذة، ملحمة النصف الأول من الحياة سببي النساء، القتال، الغزو التفاخر وطلب الجاه. أما موضوع الأوديسة فهو رحلة العودة للمحارب المتعب، الذي مل كلية من القتال ويتشوق للسلام في داره. غير أن عليه قبل ذلك أن يجتاز رحلة ضياع، رحلة سر سحري، رحلة تظهر للوهلة الأولى وكأنها سلسلة من الهز ائم ومصادفات غامضة و هروب. 
إن رحلة أوديس عبارة عن عملية استهلاك: إذ أنه فقد كل السفن والرفاق تقريباً، إلى أن وصل

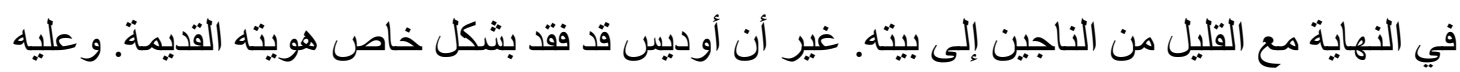

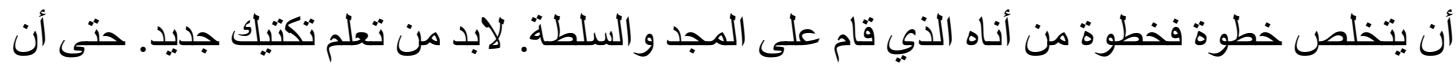

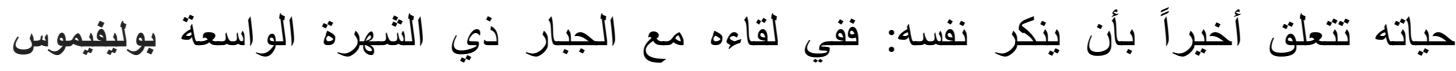

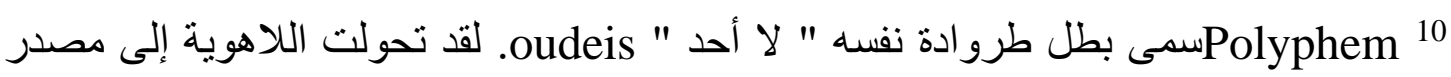

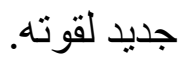
لقد انزلق أوديس أكثر من مرة في إغر اء قطع رحلة العودة و الاستسلام للحياة المريحة والمتعة

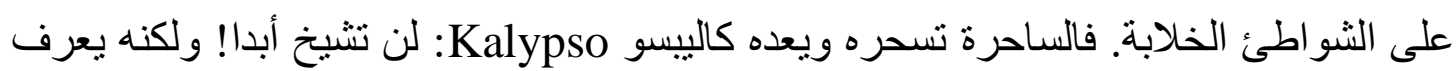

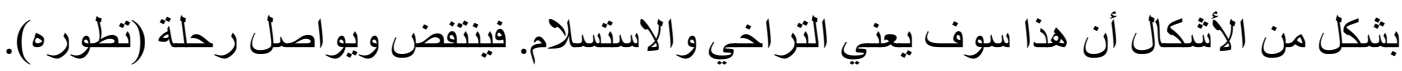

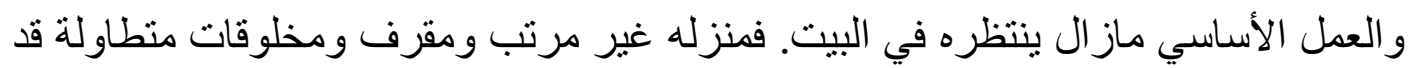

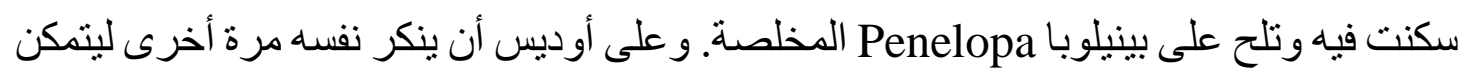
من تنظيف حظيرة الخنازير - وكي يصل في النهاية. فمن أجل اجتياز " رحلة عودة " النصف الثاني من الحياة لابد من القيام بخطوات ثلاث من التطور: التخلي عن الأهداف و القيم القديمة ونسيان أنماط السلوك المألوفة. مقاومة إغر اء الركود السعي نحو تنظيم البيت (الداخلي).

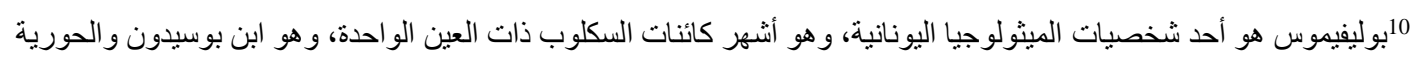

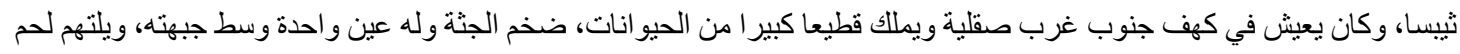
البشر ولا يقيم وزنا لقانون إلهي أو بشري. (الموسوعة)

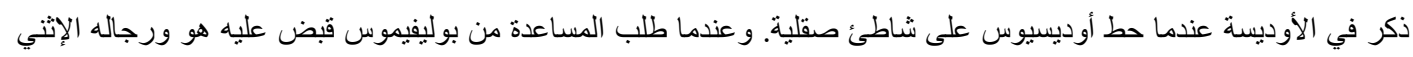

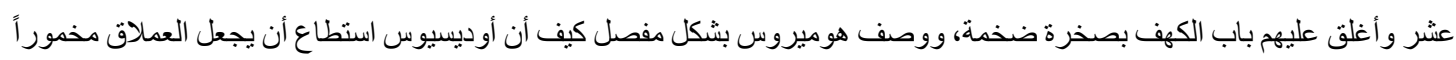

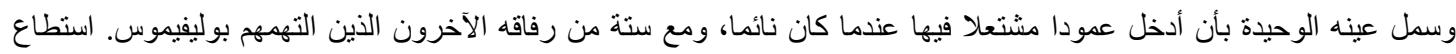

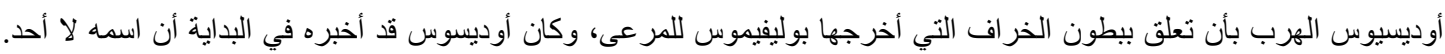

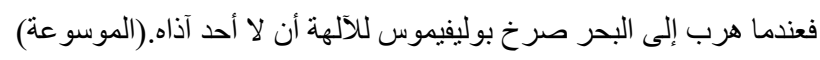

